\title{
QUESTÕES TEÓRICO-METODOLÓGICAS DA ABORDAGEM (AUTO)BIOGRÁFICA NO VI CIPA
}

\section{SANDRA NOVAIS SOUSA}

Universidade Federal de Mato Grosso do Sul

\section{JACIRA HELENA DO VALLE PEREIRA ASSIS}

Universidade Federal de Mato Grosso do Sul

\section{ELIANE GREICE DAVANÇO NOGUEIRA}

Universidade Estadual de Mato Grosso do Sul

O presente artigo apresenta reflexões sobre as questões teórico-metodológicas e epistemológicas que perpassam a abordagem (auto)biográfica nas pesquisas do campo educacional. Procurou-se fazer uma análise dos dez autores mais citados nos artigos aprovados para comunicação oral, na última edição do CIPA, identificar a qual ou quais linhas epistemológicas estes autores fazem referências, implícita ou explicitamente, em seus escritos, bem como de que forma conceituam os recursos biográficos ou (auto)biográficos em questão: como técnica ou como método de pesquisa. O objetivo foi o de realizar um mapeamento dos direcionamentos epistemológicos dos autores que embasaram teoricamente a produção científica divulgada na última edição do Congresso Internacional de Pesquisa (Auto)biográfica, observando, assim, quais os enfoques privilegiados em cada eixo temático, e se há ou não coincidências entre eles. Como resultados principais, apontamos, por um lado, a diversidade de conceitos e entendimentos dos pesquisadores quanto ao (auto)biográfico, sugerindo uma pluralidade de enfoques epistemológicos, que priorizam ora os aspectos sociológicos, ora os históricos ou psicológicos, no tratamento das narrativas e histórias de vida das pesquisas em educação. Por outro lado, há um número, ainda que reduzido, de pesquisadores que se posicionam epistemologicamente, reivindicando o status de método para o (auto)biográfico.

Palavras-chave: Epistemologia. VI CIPA. Abordagem (Auto)biográfica. Pesquisa em Educação. Método e Técnica.

\section{ABSTRACT THEORETICAL-METHODOLOGICAL APPROACH ISSUES (AUTO)BIOGRAPHICAL IN VI CIPA}

This paper presents theoretical-methodological and epistemological 
issues that permeating the approach (auto) biographical in educational research. We have analyzed the ten most cited authors in the articles approved for oral presentation in the latest issue of the CIPA, identify which or which epistemological lines these authors referred, implicitly or explicitly, in his writings, as well as how conceptualize the biographical resources or (auto) biographical concerned: as technical or as a research method. The aim was to carry out a mapping of the epistemological directions of the authors who served as theoretical basis for the scientific production published in the latest issue of the International Research Congress (Auto) Biographical and what the various approaches in each thematic area, and whether or not coincidences between them. The main results, we point out, on the one hand, the diversity of concepts and understandings of the researchers on the (auto) biographical, suggesting a plurality of epistemological approaches, which now prioritize the sociological aspects, either the historical or psychological treatment of narratives and stories of life in education research. On the other hand, a number, albeit reduced of researchers that are positioned epistemologically, claiming an autonomous status to the method of (auto) biographical. Keywords: Epistemology. VI CIPA. Approach (Auto)biographical. Research in Education. Method and Technique.

\section{CUESTIONES TEÓRICO-METODOLÓGICAS Y EPISTEMOLÓGICAS DE LA PERSPECTIVA (AUTO) BIOGRÁFICA EN EL VI CIPA}

En este trabajo se reflexiona sobre los aspectos teóricos y metodológicos y epistemológicos que impregnan el enfoque (auto) biográfica de investigación en el campo de la educación. Tratamos de hacer un análisis de los diez autores más citados en los artículos aprobados para su presentación oral en el último número de la CIPA, identificar cuál o cuáles líneas epistemológicas estos autores hace referencia, implícita o explícitamente, en sus escritos, así como la forma de conceptualizar el recursos biográficos o (auto) biográfica refiere: como técnica o como método de investigación. El objetivo era llevar a cabo un mapeo de las direcciones epistemológicas de los autores embasaram teóricamente la producción científica publicada en el último número del Congreso Internacional de Investigación (auto) biográfica observación, por lo que los diversos enfoques en cada área temática, y si desajustes entre ellos. Los principales resultados, se señalan, por un lado, la diversidad de conceptos e interpretaciones de los investigadores en el (auto)biográfico, lo que sugiere una pluralidad 
de enfoques epistemológicos, que ahora prioridad a los aspectos sociológicos, ya sea el tratamiento histórico o psicológico de relatos e historias de la vida en la investigación en educación. Por otra parte, un número, aunque sea reducido, los investigadores están posicionados epistemológicamente, reclamando un estatuto de autonomía con el método del (auto)biográfico.

Palabras clave: Epistemología. VI CIPA. Enfoque (auto)biográfico. Investigación en Educación. Método y Técnica.

\section{Introdução}

O presente artigo tem como objeto de estudo as referências teórico-metodológicas utilizadas pelos pesquisadores que tiveram seus textos aprovados e publicados nos anais do VI Congresso Internacional de Pesquisa (Auto) biográfica, realizado na capital do Rio de Janeiro, na UERJ - Universidade Estadual do Rio de Janeiro, no período de 16 a 19 de novembro de 2014, intitulado "Entre o público e o privado: modos de viver, narrar e guardar".

Como um evento que tem reunido pesquisadores do Brasil e de outros países que têm em comum a utilização de narrativas (auto) biográficas, biografias, memoriais, entrevistas narrativas, histórias de vida, entre outros dispositivos, em suas pesquisas ligadas ao campo educativo, os anais do CIPA têm compilado diferentes perspectivas de utilização da abordagem (auto)biográfica.

Nessa ótica, apresentamos como objetivo do presente estudo analisar, na produção da última edição do congresso, enviada para apresentação nos diferentes eixos temáticos, quais foram os autores mais citados por esses participantes, em seus textos, a fim de perscrutar os direcionamentos teóricos e metodológicos que embasaram esta produção científica e quais os enfoques privilegiados em cada eixo temático.

Para tanto, a metodologia utilizada foi o levantamento estatístico de quantas menções aos diversos autores constavam na lista de referências bibliográficas desses artigos, em cada eixo temático. Após essa análise, selecionaram-se os dez autores mais citados, por meio do cruzamento dos dados coletados em cada eixo e procedeu-se a uma análise de suas publicações, buscando-se, especificamente, o direcionamento metodológico acerca da abordagem (auto)biográfica: se considerada como método ou como técnica de coleta de dados.

Este artigo, portanto, foi organizado de forma a contemplar, no primeiro tópico, uma visão geral do Congresso Internacional de Pesquisa (Auto)biográfica e da edição ora analisada, com a apresentação dos dados empíricos coletados acerca do VI CIPA; no segundo tópico, analisamos a produção dos autores mais citados nessa edição do CIPA, buscando em seus textos qual abordagem teórica e metodológica utilizam ao fazer uso das diversas fontes (auto) biográficas e biográficas; por fim, no terceiro tópico, problematizamos as implicações epistemológicas da utilização de narrativas, memoriais, histórias de vida e outros dispositivos (auto)biográficos, quando considerados como método de pesquisa e usados especificamente como técnica de coleta de dados.

\section{O Congresso Internacional de Pesquisa (Auto)biográfica}

O CIPA tem reunido, em suas seis edições, realizadas de 2004 a 2014, pesquisadores que utilizam a abordagem biográfica ou (auto)biográfica nas pesquisas em educação. Foi promo- 
vido, a partir da quarta edição, pela Biograph - Associação Brasileira de Pesquisa Auto(biográfica), uma associação científica, com sede em Salvador/BA, fundada em 2008, após aprovação em uma assembleia realizado no final do III CIPA (BIOGRAPH, 2008).

Dessa forma, o Congresso Internacional de Pesquisa (Auto)biográfica nasce, segundo seus organizadores, pelo desejo demonstrado por pesquisadores de diversos países em estreitarem laços de pesquisa, de tal forma que se pudesse constituir uma rede de pesquisadores, intercontinental, em investigação (auto) biográfica (BIOGRAPH, 2008). No site oficial da Biograph, encontramos informações acerca das edições anteriores do Congresso (Cf. Quadro 1).

Quadro 1 - Edições anteriores do CIPA

\begin{tabular}{c|l|c|l}
\hline Edição & \multicolumn{1}{|c|}{ Local } & \multicolumn{1}{|c}{ Data } & \multicolumn{1}{c}{ Tema } \\
\hline I & Porto Alegre/RS & $8-11 / 09 / 2004$ & A aventura (auto) biográfica: teoria e empiria \\
II & Salvador/BA & $10-14 / 09 / 2006$ & Tempos, narrativas e ficções: a invenção de si \\
III & Natal/RN & $14-17 / 09 / 2008$ & (Auto)biografia: formação, territórios e saberes \\
IV & São Paulo/SP & $26-29 / 07 / 2010$ & Espaço (Auto)biográfico: artes de viver, conhecer e formar \\
V & Porto Alegre/RS & $16-19 / 10 / 2012$ & Pesquisa (auto)biográfica: lugares, trajetos e desafios \\
\hline
\end{tabular}

Fonte: Adaptado de Biograph (2010).

A importância do Congresso Internacional de Pesquisa (Auto)biográfica pode ser notada pelo crescente volume de publicações lançadas, um total de 33 (trinta e três) livros, considerando-se as seis edições do evento, que têm servido como umas das principais fontes de referência, no Brasil, para os pesquisadores que utilizam essa abordagem em suas investigações.

O Congresso Internacional de Pesquisa (Auto)biográfica surge em um contexto histórico em que essa modalidade de pesquisa busca maior afirmação no mundo acadêmico, nacional e internacional. Ao eleger a abordagem (auto)biográfica como método de pesquisa, ou ao utilizar as fontes biográficas e autobiográficas, como dados de uma pesquisa, o investigador assenta-se em diretrizes vinculadas à valorização das subjetividades, dos processos memorialísticos e das histórias de vida na

1 Informações disponiveis em: <http://www.biograph. org.br/index.php?option=com_content\&view=category\&layout=blog\&id=40\&|temid=76>. Acesso em: 14 abr. 2016. construção do conhecimento sobre os processos inerentes ao campo educacional.

Dessa forma, o Congresso Internacional de Pesquisa (Auto)biográfica instaura-se em um momento de intensa fertilidade e consolidação da busca por formas alternativas de pesquisa, que deem conta da complexidade do cenário social e, sobretudo, educativo.

\section{O VI CIPA}

O VI Congresso Internacional de Pesquisa (Auto)biográfica constituiu-se de: duas conferências (abertura e encerramento); sete mesas-redondas, com a participação dos pesquisadores/autores de diferentes cidades e Estados brasileiros e de diversos países - Bélgica, França, Itália, Espanha, México, Argentina, Colômbia, Peru, Porto Rico e Portugal; vinte e um simpósios; quatro sessões de comunicação, distribuídas nos três dias e referentes aos sete eixos; quatro sessões de conversa, também organizadas para receber os sete eixos nos três dias do congresso; e três sessões de pôsteres, 
uma em cada dia do CIPA (MIGNOT; SOUZA; BRAGANÇA, 2014).

Tendo como tema central "Entre o público e o privado: modos de viver, narrar e guardar", o VI CIPA reuniu congressistas provenientes de uma "[...] rica multiplicidade de categorias profissionais: professores da educação superior e básica, museólogos, arquivistas, escritores e bibliotecários" (MIGNOT; SOUZA; BRAGANÇA, 2014, p. 9).

Quadro 2 - Distribuição dos congressistas por categoria

\begin{tabular}{l|c}
\hline Categoria & Quantidade \\
\hline Estudantes de graduação & 123 \\
\hline Estudantes de pós-graduação & 338 \\
Professores da educação básica & 173 \\
Professores do ensino superior & 271 \\
\hline Total de inscritos (brasileiros) & 905 \\
\hline Total de inscritos estrangeiros & 29 \\
\hline Total geral & $\mathbf{9 3 4}$ \\
\hline
\end{tabular}

Fonte: Mignot, Souza e Bragança (2014, p. 12)

O quadro de distribuição de categorias para a inscrição no evento indica que, no VI CIPA, foram submetidos para avaliação trabalhos de "[...] professores-pesquisadores do ensino superior e da educação básica, estudantes de graduação e pós-graduação e participantes de movimentos sociais" (MIGNOT; SOUZA; BRA-
GANÇA, 2014, p. 12).

Segundo os anais do evento, do total de congressistas inscritos, 888 (oitocentos e oitenta e oito) enviaram trabalhos, totalizando $902^{2}$ (novecentos e dois) trabalhos científicos. O Quadro 3 apresenta como esses trabalhos se distribuem pelos sete eixos temáticos.

Quadro 3 - Trabalhos científicos submetidos por eixo temático

\begin{tabular}{l|c}
\hline Eixo temático & Quantidade \\
\hline Eixo 1 Pesquisa (auto) biográfica, fontes e questões & 89 \\
\hline Eixo 2 Espaços formativos, memórias e narrativas & 515 \\
\hline Eixo 3 Narrativas digitais, memórias e guarda & 30 \\
\hline Eixo 4 Infância, aprendizagem e exercício da escrita & 39 \\
\hline Eixo 5. (auto)biografia, literatura e história & 59 \\
\hline Eixo 6 Escrita de si, resistência e empoderamento & 77 \\
\hline Eixo 7 histórias de vida, gênero e educação & 93 \\
\hline Total & $\mathbf{9 0 2}$ \\
\hline
\end{tabular}

Fonte: Adaptado de Mignot, Souza e Bragança (2014, p. 9)

2 Um autor poderia submeter até dois trabalhos. 
Os organizadores explicam que "Dos 902 trabalhos submetidos, 886 foram selecionados e, destes, 743 foram inscritos e [...] apresentados. 0 quantitativo de trabalhos por eixo aponta para uma multiplicidade de lugares em que a pesquisa autobiográfica vem se constituindo [...]" (MIGNOT; SOUZA; BRAGANÇA, 2014, p. 12).

Quadro 4 - Trabalhos apresentados no VI CIPA ${ }^{3}$

\begin{tabular}{l|c|c|c|c|c|c|c|c}
\multicolumn{1}{c|}{} & Eixo 1 & Eixo 2 & Eixo 3 & Eixo 4 & Eixo 5 & Eixo 6 & Eixo 7 & Total \\
\hline Sessões de Comunicação & 43 & 246 & 16 & 30 & 38 & 43 & 50 & 466 \\
Sessões de Conversa & 10 & 36 & 03 & 06 & 10 & 07 & 07 & 79 \\
Pôsteres & 06 & 80 & 04 & 09 & 03 & 03 & 11 & 116 \\
\hline Total por eixo & $\mathbf{5 9}$ & $\mathbf{3 6 2}$ & $\mathbf{2 3}$ & $\mathbf{4 5}$ & $\mathbf{5 1}$ & $\mathbf{5 3}$ & $\mathbf{6 8}$ & $\mathbf{6 6 1}$ \\
\hline
\end{tabular}

Fonte: Baseado em Mignot, Souza e Bragança (2014)

Assim, a partir dos diferentes lugares dos quais partiram as pesquisas submetidas e apresentadas, ora destacando questões de formação, de método ou de gênero, passando por literatura, narrativas infantis, de professores da educação básica ou superior, que apontavam para a configuração de espaços formativos ou questões de resistência e empoderamento, os trabalhos apresentados no VI CIPA evidenciaram, sobretudo, as vozes dos sujeitos que narram, constroem, significam e ressignificam suas histórias de vida, pessoais ou profissionais. Po- rém, isso não significa uma unidade metodológica ou teórica. A análise das referências bibliográficas listadas pelos autores demonstra uma pluralidade de enfoques e pontos de partida, de objetos, objetivos e perspectivas de pesquisa.

O Quadro 5 traz, em ordem crescente, o resultado da contagem realizada por meio da ferramenta de classificação do Excel, observando-se as listas de referências de todos os artigos, dos eixos 1 a 7, com os nomes dos dez autores mais referenciados nos trabalhos apresentados no VI CIPA.

Quadro 5 - Os dez autores mais citados no VI CIPA

\begin{tabular}{|c|c|c|}
\hline \multicolumn{2}{|r|}{ Autor } & № de referências \\
\hline $1 \underline{0}$ & NÓvOA, António & 266 \\
\hline $2 \underline{0}$ & JOSSO, Marie-Christine & 193 \\
\hline 30 & SOUZA, Elizeu Clementino & 157 \\
\hline 40 & FREIRE, Paulo & 155 \\
\hline 50 & DELORY-MOBERGER, Christine & 119 \\
\hline $6 \underline{0}$ & LARROSA, Jorge Bondía & 104 \\
\hline $7 \underline{0}$ & PASSEGGI, Maria da Conceição & 99 \\
\hline 8o & BAKHTIN, Michael & 85 \\
\hline 90 & TARDIF, Maurice & 80 \\
\hline 10 은 & BOURDIEU, Pierre & 71 \\
\hline
\end{tabular}

3 Não estão incluídos os trabalhos apresentados em mesas-redondas e simpósios que somam, ao todo, oitenta e dois trabalhos. 
Ao fazer, estatisticamente, o cruzamento das referências utilizadas pelos autores que enviaram seus textos para os diferentes eixos, notamos que, em alguns deles, como o Eixo 1 [Pesquisa (auto)biográfica, fontes e questões] e o Eixo 2 (Espaços formativos, memórias e narrativas), houve mais coincidência de autores referenciados, sendo nítida a identificação dos autores mais citados. Em outros eixos, como o Eixo 4 (Infância, aprendizagem e exercício da escrita) e Eixo 5 [(Auto)biografia, literatura e história], dificilmente se repetia o nome de um autor, de um artigo para o outro, havendo uma significativa variedade de autores. 0 autor mais referenciado, por exemplo, no Eixo 3 (Narrativas digitais, memórias e guarda) teve sete livros nas listas de referências, sendo três no mesmo artigo; os outros, empataram em três ou quatro referências, em um total de 23 artigos. Ou seja, houve uma quantidade maior de autores diferentes citados em cada trabalho, o que se repetiu nos eixos 6 e 7 .

No próximo tópico, analisaremos as produções mais citadas desses autores, a fim de investigar, conforme apontamos na introdução deste estudo, como esses dez autores consideram a utilização de narrativas, memoriais, histórias de vida e outros dispositivos (auto)biográficos: como método de pesquisa ou como técnica de coleta de dados.

\section{A abordagem (auto)biográfica no VI CIPA: questões teórico- metodológicas}

O autor mais citado e que figurou nas listas de referências de todos os sete eixos do congresso foi o professor português António Nóvoa. De todos os livros, capítulos de livros e artigos de António Nóvoa citados pelos autores do VI CIPA, "O método (auto)biográfico e a formação" (NÓVOA; FINGER, 2000), "Vida de Professores" (NÓVOA, 1992a) e "Os professores e sua forma- ção" (NÓVOA, 1992b) foram os mais referenciados. Como bem demonstra o título do primeiro livro aqui mencionado, Nóvoa defende, em vários de seus textos, o estatuto de método à abordagem (auto)biográfica.

$\mathrm{Na}$ introdução de "Os professores e sua formação" (NÓVOA, 1992b), este autor afirma que realizou:

[...] um esforço de sistematização metodológica
procurando categorizar as abordagens (auto)
biográficas com base nos objectivos (essencial-
mente teóricos, relacionados com a investiga-
ção; essencialmente práticos, relacionados com
a formação, essencialmente emancipatórios,
relacionados com a investigação-formação) e
nas dimensões (pessoa do professor; práticas
dos professores; profissão de professor) que
as diferentes perspectivas privilegiam. (NÓVOA,
1992b, p. 13)

Em seu esforço de sistematização, o autor admite a multiplicidade de enfoques que a abordagem (auto)biográfica pode apresentar, afirmando que cada estudo tem uma configuração própria. No entanto, observa que “[...] a qualidade heurística destas abordagens, bem como as perspectivas de mudança de que são portadoras, residem em grande medida na possibilidade de conjugar diversos olhares disciplinares, de construir uma compreensão multifacetada [...] de vários saberes" (NÓVOA, 1992b, p. 20).

Assim, para Nóvoa, “[...] as histórias de vida e o método (auto)biográfico integram-se no movimento actual que procura repensar as questões da formação, acentuando a idéia que 'ninguém forma ninguém' e que 'a formação é inevitavelmente um trabalho de reflexão sobre os percursos de vida' [...]" (NÓVOA, 1988, p. 116, grifos do autor, apud SOUZA, 2006, p. 26).

Marie-Christine Josso foi a segunda autora mais referenciada no $\mathrm{VI} C \mathrm{CIPA}$. No artigo “ $\mathrm{A}$ transformação de si a partir da narração de histórias de vida", em um relato (auto)biográfico, a autora afirma: 
Eu espero mostrar uma vez mais, por uma opção de escrita biográfica, a fecundidade do paradigma do singular plural, associado ao paradigma do experiencial, pelo viés da abordagem biográfica. [...] Que a abordagem biográfica como suporte empírico para a reflexão compreensiva da formação de si como sujeito tenha exigido uma 'multirreferencialidade', dava-me enfim o sentimento de que o saber universitário podia, por esse viés, sair de sua Torre de Babel, fazer sentido para o cidadão comum e ser para ele um saber de uso quotidiano [...]. (JOSSO, 2007, p. 432)

O que Josso (2007) denomina de "paradigma do singular plural"? Para a autora, esse paradigma "não pertence a nenhuma disciplina em particular", pois se trata de uma "invenção de si", construída narrativamente a partir da escrita das experiências pessoais ou, como define a autora:

[...] da retomada parcial, na colocação em perspectiva do presente e do futuro, graças a esse olhar retrospectivo, por um lado e, por outro, devido ao fato de que cada acontecimento ou contexto singular remete imediatamente a referenciais coletivos (socioculturais e sócio-históricos), estejamos ou não conscientes disso. (JOSSO, 2007, p. 435)

Josso, portanto, vê na abordagem biográfica uma potencialidade formativa, que "[...] ainda necessita de embasamento teórico suficiente por um lado e, por outro, de um tratamento suficientemente liberado das convenções e reduções ligadas ao 'politicamente correto' e ao 'epistemologicamente correto' [...]" (JOSSO, 2007, p. 432). Para a pesquisadora, os “[...] modelos funcionalistas e estruturo-marxistas [evidenciam] os conceitos de classe, de papel e de normas culturais e sociais interiorizados como fundamento da construção da identidade e a fonte de um sentimento de existência", porém, "não dão conta" de explicar como, "[...] nas sociedades em mutações estruturais como as que conhecemos a partir do fim dos anos
60 , as individualidades se arranjam para reorganizar suas pertenças e seus comportamentos, seus valores e seus posicionamentos sociais e culturais [...]" (JOSSO, 2007, p. 418).

Não denomina o biográfico nem como método, nem como técnica, mas aposta em um paradigma do singular plural, associado à escrita autobiográfica e à formação de adultos, que possui potencial tanto "[...] para desenvolver o trabalho de integração e de transcendência das disciplinas herdadas do século XIX" e da visão de "saber recortado" que elas propagam, quanto para promover uma nova "[...] concepção das carreiras dos pesquisadores, de seus itinerários de formação e das modalidades de reconhecimento do valor de seus trabalhos" (JOSSO, 2007, p. 432).

Dentre os inúmeros trabalhos de Elizeu Clementino de Souza, também na lista dos mais referenciados no VI CIPA, procuramos, no artigo "A arte de contar e trocar experiências: reflexões teórico-metodológicas sobre história de vida em formação", qual a concepção da abordagem (auto)biográfica defendida por este autor. Logo no início do texto, após situar essa abordagem no âmbito da História Oral, no campo da Sociologia, chama a atenção para a “[...] heterogeneidade em torno da temática e do caminho desta abordagem de investigação/ formação proveniente de diferentes campos e disciplinas do saber humano, configurando-se numa prática multidisciplinar e polissêmica" (SOUZA, 2006, p. 25). Apresenta, em seguida, as diversas denominações que essa abordagem pode receber, porém, delimita que:

Nas pesquisas na área de educação adota-se a história de vida, mais especificamente, o método autobiográfico e as narrativas de formação como movimento de investigação-formação, seja na formação inicial ou continuada de professores/professoras seja em pesquisas centradas nas memórias e autobiografias de professores. (SOUZA, 2006, p. 26) 
Nesse texto, o autor deixa clara a sua compreensão quanto ao aspecto que procuramos evidenciar neste breve estudo, ao afirmar: "Evidencio [...] que a abordagem biográfica tanto é método, porque logrou no seu processo histórico vasta fundamentação teórica, quanto é técnica, porque também gozou de conflitos, consensos e implicações teórico-metodológicas sobre a sua utilização" (SOUZA, 2006, p. 29, grifos nossos). No entanto, no que se refere ao seu posicionamento pessoal, afirma:

Os caminhos trilhados desde o início do século $\mathrm{XX}$ e os embates travados em diferentes campos do conhecimento têm permitido melhor compreender e reafirmar a abordagem biográfica e a utilização da narrativa (auto) biográfica como opção metodológica para a formação de professores, visto que a mesma possibilita inicialmente um movimento de investigação sobre o processo de formação e, por outro lado, possibilita, a partir das narrativas (auto) biográficas, entender os sentimentos e representações dos atores sociais no seu processo de formação e autoformação. (SOUZA, 2006, p. 35, grifos nossos)

Assim, podemos situá-lo entre os autores que consideram a abordagem (auto)biográfica como método de pesquisa autônomo, embora reconheça que, igualmente e concomitantemente, possa ser utilizada como técnica de recolha de dados de pesquisa.

Outro autor bastante referenciado em todos os eixos temáticos do VI CIPA foi Paulo Freire. Acerca de seu posicionamento quanto ao tema de nosso estudo, Aliança (2011), citando o artigo "O legado de Paulo Freire para a pesquisa (auto)biográfica" (CASALI, 2008), explica que Paulo Freire, como um "docente em permanente formação de si mesmo", utiliza em seu processo formativo e no método que criou para a alfabetização de adultos, a narrativa de si. Segundo Casali (2008, p. 34, apud ALIANÇA, 2011, p. 207):

Não consta que Paulo Freire tenha se referido explicitamente à pesquisa (auto)biográfica como um aporte teórico-metodológico particularmente importante para a pesquisa em educação e para uma prática educativa crítica. Não obstante, não é difícil percebê-lo e inscrevê-lo como um autor inteiramente sintonizado com esse aporte, inclusive porque ele o praticou espontaneamente, de distintas maneiras, ao longo de todo o seu percurso intelectual, político e pedagógico. Disso temos vários sinais.

A autora cita ainda um trecho em que Casali (2008, p. 35, apud ALIANÇA, 2011, p. 207) retoma uma declaração dada informalmente pela viúva de Paulo Freire, Ana Maria: "Paulo compreendia que as histórias de vida eram (são) muito importantes: quem fala sobre sua vida se sente sujeito da história".

Assim, embora não se possa situar Paulo Freire em um dos conceitos sobre a abordagem biográfica que analisamos neste texto (método ou técnica), podemos inferir que a utilização de narrativas de si, o ato de narrar sua própria vida e ressignificá-la, não eram estranhos à abordagem e ao método de pesquisa e de formação utilizado pelo autor.

No que se refere à quarta autora mais citada em textos do VI CIPA, Christine DeloryMomberger, logo no início de artigo “Formação e Socialização: os ateliês biográficos de projeto", afirma que "A prática de histórias de vida em formação fundamenta-se sobre a ideia de apropriação que o indivíduo faz de sua própria história ao realizar a narrativa de sua vida. É nesse quadro de autoformação que o método de histórias de vida foi definido [...]" (DELORYMOMBERGER, 2006, p. 361), citando, logo em seguida, Gastón Pineau e Marie Michèle, para embasar sua afirmação. É na perspectiva das histórias de vida como método de formação de adultos que explica:

Do ponto de vista epistemológico e metodológico, os pressupostos teóricos que inspiram as tendências de formação pelas histórias de vida podem ser apresentadas sinteticamente sob dois aspectos: o primeiro atém-se ao estatuto 
da narrativa na experiência que o sujeito faz de si mesmo, mediante a produção de sua história; o segundo, à dimensão de projeto constitutivo da história de vida e do processo de formação (DELORY-MOMBERGER, 2006, p. 361).

A autora denomina "[...] biografización al conjunto de operaciones y de comportamientos por medio de los cuales los individuos trabajan para darse una forma propia en la que se reconocen a sí mismos y se hacen reconocer por los otros"4 (DELORY-MOMBERGER, 2014, p. 699). Assim, nessa experiência de (auto)biografar ou de dar forma própria ao modo como se reconhecem e se fazem reconhecer aos outros, os sujeitos colocam-se em processo de formação. A mediação dessa formação é apresentada pela autora por meio do conceito de Ateliês Biográficos de Projeto, um dispositivo que, segundo ela, destina-se a "[...] trabalhar sobre as representações que os formados dão nos relatos de suas experiências de formação, reinscrevendo-as na perspectiva de um projeto" (DELORY-MOMBERGER, 2006, p. 366).

O conceito de experiência, utilizado por Delory-Momberger, guarda semelhanças com a forma com que Jorge Bondía Larrosa, o quinto autor mais citado em nossa pesquisa, conceitua o termo: "Experiência é o que nos passa, o que nos acontece, o que nos toca. Não o que se passa, não o que acontece, ou o que toca" (LARROSA, 2002, p. 21). Para o autor, "[...] cada um de nós já se encontra imerso em estruturas narrativas que pré-existem e que organizam de um modo particular a experiência" (LAROSSA, 1996, p. 471).

Sob essa ótica, o autor se inscreve entre aqueles que observam, nas escritas de si dos sujeitos em formação, uma dimensão potencialmente inspiradora na reconstrução do sen-

4 A autora denomina "biografização ao conjunto de operações e de comportamentos por meio dos quais os indivíduos trabalham para dar-se uma forma própria em que se reconhecem a si mesmos e se fazem reconhecer pelos outros" (tradução nossa). tido de suas experiências. Nessa perspectiva, os sujeitos se apresentam "[...] como sujeitos confessantes; não em relação a uma verdade sobre si mesmos que lhes é imposta de fora, mas em relação a uma verdade sobre si mesmos que eles mesmos devem contribuir ativamente para produzir" (LARROSA, 1994, p. 54).

Para esse autor, os "[...] los estudios sobre autobiografias o sobre historias personales [são] un campo de trabajo muy fecundo y muy vivo, atravesado por discusiones sobre cuestiones teóricas, metodológicas, éticas, políticas y culturales"5 (LARROSA, 2004, p. 11), que sinalizam questões de poder e de validação sobre o estatuto de cientificidade dos escritos sobre experiências pessoais e docentes. Embora não se posicione explicitamente sobre questões de método e técnica, pode-se inferir que suas ideias acerca dos escritos (auto) biográficos não permitiriam supor que estes fossem postos à prova de veracidade, a partir do cruzamento com outros dados documentais, como é feito quando se considera essas fontes como dados de pesquisa fundamentada em uma perspectiva teórica de cunho historiográfico ou de investigação de determinado fenômeno social.

Ademais, citando Ricoeur (1985, p. 213, apud LAROSSA, 2004, p. 17), argumenta “Es contando nuestras propias historias que nos damos a nosotros mismos una identidad. [...] Y es pequeña la diferencia si esas historias son verdaderas o falsas, tanto la ficción como la historia verificable nos provee de una identidad" ${ }^{\text {. }}$.

Para Maria da Conceição Passeggi, também entre as autoras mais citadas nos anais do $\mathrm{VI}$

5 “[...] os estudos sobre autobiografias ou sobre histórias pessoais [são] um campo de trabalho muito fecundo e muito vivo, atravessado por discussões sobre questões teóricas, metodológicas, éticas, políticas e culturais" (tradução nossa).

6 “É contando nossas próprias histórias que damos a nós mesmos uma identidade. [...] E é pequena a diferença se essas histórias são verdadeiras ou falsas, tanto a ficção como a história verificável nos provê de uma identidade" (tradução nossa). 
CIPA, a leitura de Larrosa nos permite redimensionar o sentido de experiência, enquanto que a aproximação dos textos de Ricouer "[...] tem nos ajudado a aprofundar a reflexão sobre a compreensão da consciência histórica, que emerge no ato de dar sentido à experiência vivida" (PASSEGGI, 2011, p. 149). A autora figura entre os estudiosos que entendem "a pesquisa com narrativas (auto)biográficas como método e prática de formação" (PASSEGGI, 2014, p.16). No entanto, a pesquisadora vem se destacando em produções que afirmam a potencialidade do que denomina "mediação biográfica" em "grupos reflexivos", que define como "prática de formação" e não como método de pesquisa (PASSEGGI, 2011).

Para delimitar a diferença entre sua proposta e outras formas de agrupamento com produção autobiográfica, Passeggi (2011) explica que nas pesquisas educacionais duas noções de grupo são cada vez mais encontradas: o grupo focal e o grupo de discussão. Em ambos, a interação do grupo com o pesquisador dá-se com vistas à construção de dados empíricos e à produção de conhecimento. Sua proposta, embora parta "da literatura sobre as histórias de vida em formação, no domínio da formação de adultos, que trabalha a ideia de co-construção do sentido entre o formador, o grupo e a pessoa em formação", indica a pretensão de proporcionar um ambiente formativo em que "[...] a experiência vivida permita experienciar questões de ordem afetiva, cognitiva, sociocultual, que vão além daquelas de caráter puramente teórico e metodológico" (PASSEGGI, 2011, p. 150).

Em uma menção a Bakhtin, nosso oitavo autor em número de referências no VI CIPA, Passeggi (2011) aponta para a importância da objetivação do pensamento por meio da linguagem, pois uma expressão, uma vez emitida:

[...] exerce um efeito reversivo sobre a atividade mental: ela põe-se então a estruturar a vida interior, a dar-lhe uma expressão ainda mais definida e mais estável. Essa ação reversível da expressão bem formada sobre a atividade mental (isto é, a expressão interior) tem uma importância enorme que deve ser considerada. (BAKHTIN; VOLOCHINOV, 1985, p. 118 apud PASSEGGI, 2011, p. 153)

Para a autora, é nesse sentido que as narrativas (auto)biográficas são formadoras. Bakhtin (1997, p. 166), por sua vez, afirma acerca da escrita de si que o "[...] valor biográfico pode organizar não só a narração sobre a vida do outro, mas também o vivenciamento da própria vida e a narração sobre a minha própria vida, pode ser forma de conscientização, visão e enunciação da minha própria vida".

Para Bakhtin (1997, p. 166), o autor de biografia:

[...] é aquele outro possivel, pelo qual somos mais facilmente possuídos na vida, que está conosco quando nos olhamos no espelho, quando sonhamos com a fama, fazemos planos externos para a vida; é o outro possivel, que se infiltrou na nossa consciência e frequentemente dirige nossos atos, apreciações e visão de nós mesmos ao lado do nosso eu-para-si; é o outro na consciência [...].

Nessa perspectiva bakhtiniana da atividade autobiográfica, também não se pode inferir, a exemplo de como analisamos Paulo Freire, que o valor heurístico da narrativa de si possa ser limitado pelo seu uso como técnica que, ao coletar dados para verificar situações específicas de práticas pedagógicas, fatos sociais ou determinados contextos educativos, precisem ser validadas por meio do recurso a outras fontes, orais ou documentais, que comprovem sua veracidade. Para que seja utilizada nessa perspectiva, as narrativas (auto)biográficas necessitariam ser consideradas em outro contexto e para outros fins, que não passassem por essa "apreciação e visão" de si mesmos, do "eu-para-si", conforme expressa Bakhtin (1997, p. 166). 
Encontramos em Maurice Tardif, o nono autor de nossa lista, uma perspectiva de utilização das histórias de vida mais relacionada à técnica de coleta de dados. Ao referir-se a uma pesquisa feita por ele e Lessard sobre os professores do Quebec (LESSARD; TARDIF, 1996), afirma que “Embora essa pesquisa não objetivasse reconstruir a história de vida dos professores a partir de uma metodologia narrativa [...]", elementos das histórias de vida dos docentes "[...] foram espontaneamente abordados pelos professores interrogados, ou postos em evidência pela análise" (TARDIF; RAYMOND, 2000, p. 21). Ainda que não tenha optado por uma abordagem (auto)biográfica na pesquisa mencionada, o autor atesta, acerca da relação entre história de vida e saberes dos professores:

Em última análise, o saber-ensinar tornar-se-ia a coincidência perfeita entre a personalidade do ator e o papel do agente, ambos justificando-se assim mutuamente. Em suma, o que essa lógica circular de justificação revela é a função de mediação que a história de vida exerce entre os saberes do indivíduo e os papéis e atitudes das equipes de trabalho: a 'personalidade', enquanto racionalização construída a partir do sucesso como aluno e como professor, mostra como o indivíduo responde às normas institucionalizadas e como a equipe de trabalho, em troca, seleciona e valoriza essas 'personalidades' que se acham em conformidade com os papéis institucionalizados. (TARDIF; RAYMOND, 2000, p. 21)

Para Tardif (2009, p. 17), o “[...] saber dos docentes era, antes de qualquer coisa, narrativo e experiencial, e não apenas teórico e conceitual". A utilização de histórias de vida foi considerada, portanto, como dispositivo para a pesquisa com professores, por sua possibilidade de acessar dados que podem auxiliar na proposição de políticas de formação docente, a partir dos saberes "narrativos e experienciais" relatados pelos professores.
Por fim, em relação a Pierre Bourdieu, o décimo autor mais citado conforme nossa pesquisa, percebemos que a maioria das referências a ele foram citando o texto "A ilusão biográfica" (1998), escrito originalmente em 1986, ora para refutar suas argumentações, ora para situar e justificar a escolha feita de autores, em função de tentar fugir das armadilhas que fariam uma narrativa ser vista como uma ilusão. No entanto, não tomaremos este texto como base para analisar a posterior relação do autor com as histórias de vida. Optamos por analisar "A miséria do mundo" (BOURDIEU, 2011), pelo fato de que, nesse livro, o autor coordenou um intenso trabalho de entrevistas que resultaram, segundo ele, em "[...] depoimentos que homens e mulheres nos confiaram a propósito de sua existência e de sua dificuldade de viver", ou, em outras palavras, em histórias de vida.

No capítulo "Compreender" desse livro, o autor traz uma série de reflexões acerca das implicações da situação de interação social entre entrevistador e entrevistado, em que pode ocorrer o que denomina de "violência simbólica", o que, inclusive, pode afetar as respostas. Assim, afirma que "Só a reflexividade, que é sinônimo de método, mas uma reflexividade reflexa, baseada num 'trabalho', num 'olho sociológico', permite perceber e controlar no campo, na própria condução da entrevista, os efeitos da estrutura social na qual ela se realiza" (BOURDIEU, 2011, p. 694). Para o autor, a entrevista que recolhe histórias de vida deve “tentar reduzir ao máximo a violência simbólica", por meio da instauração de uma "[...] relação de escuta ativa e metódica, tão afastada da pura não-intervenção da entrevista não dirigida, quanto do dirigismo do questionário" (BOURDIEU, 2011, p. 695).

Podemos afirmar que o autor claramente enfatiza as peculiaridades metodológicas de uma pesquisa com histórias de vida. Para ele, 
a postura do pesquisador deve associar "[...] a disponibilidade total em relação à pessoa interrogada, a submissão à singularidade de sua história particular [...] com a construção metódica, forte, do conhecimento das condições objetivas, comuns a toda uma categoria" (BOURDIEU, 2011, p. 695). Essas condições objetivas passam pelo conhecimento da disparidade que pode haver em relação ao capital linguístico, cultural ou mesmo econômico, entre entrevistador e entrevistado, o que pode resultar em uma interação desigual.

Pode-se perceber, nesse livro, o cuidado metodológico que o autor enfatiza para que em uma entrevista, ainda que tomada como técnica de coleta de dados, haja respeito, tanto no que se refere à interação entre pesquisador e pesquisado, como na transcrição e no tratamento desses dados de pesquisa.

\section{Considerações finais}

O objetivo deste estudo, conforme apontamos na introdução, foi realizar um mapeamento dos direcionamentos epistemológicos dos autores que embasaram teoricamente a produção científica divulgada na última edição do Congresso Internacional de Pesquisa (Auto) biográfica.

Observamos, dessa forma, que dentre os dez autores mais citados, António Nóvoa (1988; 1992a; 1992b), Elizeu Clementino de Souza (2006), Christine Delory-Momberger (2006; 2014) e Maria da Conceição Passeggi (2011; 2014) reconhecem, em seus textos, a autonomia da abordagem (auto)biográfica como método de pesquisa e como dispositivo de formação.

Jorge Larossa (1994; 1996; 2004) e Mikhail Bakhtin (1985; 1997), embora não se posicionem quanto ao aspecto que pesquisamos neste estudo, apontam para o caráter reflexivo que a escrita de si provoca nos sujeitos e que, ao construírem, em suas narrativas, uma ressig- nificação de suas vidas, o elemento ficcional presente não as invalida, ao contrário, demonstra a representação que os narradores têm de si mesmos e a forma como desejam ser vistos pelo outro. Em uma perspectiva de trabalho com as (auto)biografias como método autônomo, condicionar esses relatos a uma verificação de autenticidade, por meio do cruzamento com outros dados, seria retirar do sujeito sua autonomia para representar-se narrativamente.

Paulo Freire, igualmente, não tratou das narrativas autobiográficas como método ou como técnica de pesquisa. No entanto, seu método, criado para a alfabetização e a emancipação de adultos, pelo acesso à leitura, considerava a voz desses sujeitos e a representação que faziam do contexto social em que estavam inseridos (FREIRE, 1982).

Por fim, Maurice Tardif (LESSARD; TARDIF, 1996) e Pierre Bourdieu (2011) utilizaram a entrevista para a técnica de recolha de histórias de vidas, com objetivos diferentes, mas demonstrando o mesmo cuidado metodológico de respeito aos saberes, crenças e vozes dos entrevistados. No caso de Tardif e Lessard (1996), professores em um contexto social cheio de fragilidades; no caso de Bourdieu (2011) e sua equipe de pesquisadores, não somente professores, mas estudantes, trabalhadores, enfim, grupos sociais em situação de exclusão social.

Dessa forma, a observação das listas de referências dos autores que submeteram e tiveram seus artigos aprovados no VI CIPA apontou, como resultados principais, por um lado, a diversidade de conceitos e entendimentos dos pesquisadores quanto ao (auto)biográfico, sugerindo uma pluralidade de enfoques epistemológicos, que priorizam ora os aspectos sociológicos, ora os históricos ou psicológicos, no tratamento das narrativas e histórias de vida das pesquisas em educação. Por outro lado, há um número, ainda que reduzido, de pesquisadores que se posicionam epistemolo- 
gicamente, reivindicando um status de método para o (auto)biográfico.

A análise que fizemos dos dez autores mais citados por estes pesquisadores não indica, entretanto, que estes assumam as perspectivas desses autores na construção de seus textos. Observamos em um número considerável de artigos certo ecletismo na escolha dos referenciais que os embasaram teoricamente, colocando por vez, lado a lado, autores que não

\section{Referências}

ALIANÇA, Priscila. Pesquisa (auto)biográfica e (auto) formação crítica do professor de língua inglesa. HOLOS, Natal, ano 21, v. 4, p. 209-214, 2011.

BAKHTIN, Mikhail; VOLOCHINÓV, Viktor. Marxismo e filosofia da linguagem. São Paulo: Hucitec, 1985.

BAKHTIN, Mikhail. Estética da criação verbal. [tradução feita a partir do francês por Maria Emsantina Galvão G. Pereira; revisão da tradução Marina Appenzellerl]. 2. ed. São Paulo: Martins Fontes, 1997. (Coleção Ensino Superior).

BIOGRAPH. Associação Brasileira de Pesquisa (Auto)Biográfica. 2010. Disponivel em: <http://www. biograph.org.br/>. Acesso em: 15 abr.16.

BIOGRAPH. Associação Brasileira de Pesquisa (Auto) Biográfica. Estatuto. 2008. Disponivel em: <http:// www.biograph.org.br/index.php?option=com_content $\&$ view $=$ category $\&$ layout $=$ blog $\& i d=36 \&$ Ite $\mathrm{mid}=57>$. Acesso em: 15 abr.16.

BOURDIEU, Pierre. (Coord.). A miséria do mundo. Tradução de Mateus S. Soares Azevedo. 8. ed. Petrópolis, RJ: Vozes, 2011.

BOURDIEU, Pierre. A ilusão biográfica. In: FERREIRA, Marieta de Morais; AMADO, Janaina (Orgs.). Usos e abusos da história oral. Rio de Janeiro: Editora da FGV, 1998, p. 183-189.

BOURDIEU, Pierre. L'illusion biographique. Actes de la Recherche en Sciences Sociales, v. 62/63, p. 69-72, jun. 1986.

CASALI, Alípio. O legado de Paulo Freire para a pes- "se conversam" teoricamente. Entendemos, diante dessa observação, que se faz necessário um aprofundamento teórico e metodológico, a fim de demonstrar coerência entre os objetivos de pesquisa, o método utilizado e os autores que são eleitos para embasar, tanto os processos investigativos quanto os relatórios de pesquisa. Dessa forma, evita-se a apropriação indevida ou a interpretação equivocada das ideias dos autores referenciados.

quisa (auto)biográfica. In: PASSEGGI, Maria da Conceição; BARBOSA, Tatyana Mabel Nobre (Orgs.). Narrativas de formação e saberes biográficos. Natal: EDUFRN; São Paulo: Paulus, 2008. p. 25-43.

DELORY-MOMBERGER, Christine. Formação e socialização: os ateliês biográficos de projeto. Educação e Pesquisa, São Paulo, v. 32, n. 2, p. 359-371, mai./ago. 2006.

DELORY-MOMBERGER, Christine. Experiencia y formación: biografización, biograficidad y heterobiografía. Revista Mexicana de Investigación Educativa, Cidade do México, v. XIX, n. 62, p. 695-710, jul./set. 2014.

FREIRE, Paulo. Ação cultural para a liberdade e outros escritos. 6. ed. Rio de Janeiro: Paz e Terra, 1982. JOSSO, Marie-Christine. A transformação de si a partir da narração de histórias de vida. Educação, Porto Alegre, v. 63, n. 3, p. 413-438, set./dez. 2007.

LARROSA, Jorge. Tecnologias do eu e educação. In: SILVA, Tomaz T. O sujeito da educação. Petrópolis, RJ: Vozes, 1994. p. 35-86.

LARROSA, Jorge. Narrativa, identidade y desidentificación. In: LARROSA, Jorge. La experiencia de la lectura. Barcelona: Laertes, 1996.

LAROSSA, Jorge. Notas sobre a experiência e o saber de experiência. Revista Brasileira de Educação, Rio de Janeiro, v.2, n. 19, p. 20-28, jan./abr. 2002.

LARROSA, Jorge. Notas sobre narrativa e identidad. In: ABRAHÃO, Maria Helena Menna Barreto (Org.). A aventura (auto)biográfica: teoria e empiria. Porto Alegre: EDIPUCRS, 2004. p. 11-22.

LESSARD, Claude; TARDIF, Maurice. La profession en- 
seignante au Québec (1945- 1990). Histoire, système et structures. Montreal: Presses de l'Université de Montréal, 1996.

MIGNOT, Ana Chrystina; SOUZA, Elizeu Clementino de.; BRAGANÇA, Inês Ferreira de Souza (Orgs.) Programa e Anais do Congresso Internacional de Pesquisa (Auto)Biográfica. Versão impressa e em CD -ROM. Rio de Janeiro: BIOgraph, 2014. 88 p.

NÓVOA, António.Vidas de professores. Porto: Porto Editora, 1992a.

NÓVOA, António. Os professores e a sua formação. Lisboa: Publicações Dom Quixote, 1992b.

NÓVOA, António; FINGER, Mathias (Orgs.). 0 método (auto)biográfico e a formação. Lisboa: Ministério da Saúde/Departamento de Recursos Humanos, 2000.

NÓVOA, António; FINGER, Mathias (Orgs.). 0 método (auto)biográfico e a formação. Lisboa: Ministério da Saúde/Departamento de Recursos Humanos, 1988.

PASSEGGI, Maria da Conceição. A experiência em formação. Educação, Porto Alegre, v. 34, n. 2, p. 147156, mai./ago. 2011.
PASSEGGI, Maria da Conceição. Narrativas de crianças sobre as escolas da infância: cenários e desafios da pesquisa (auto)biográfica. Educação, Santa Maria, v. 39, n. 1, p. 85-104, jan./abr. 2014.

RICOEUR, Paul. Temps et récit. v. III. Paris: Éditions du Seuil, 1985.

SOUZA, Elizeu Clementino de. A arte de contar e trocar experiências: reflexões teórico-metodológicas sobre história de vida em formação. Educação em Questão, Natal, v. 25, n. 11, p. 22-39, jan./abr. 2006.

TARDIF, Maurice. A formação nos estabelecimentos escolares In: ENS, Teodora; VOSGERAU, Dilmeire SantAnna Ramos; BEHRENS, Marilda Aparecida (Orgs.). Trabalho do professor no espaço escolar. Curitiba: Editora da PUC do Paraná, 2009. p. 15-25.

TARDIF, Maurice; RAYMOND, Danielle. Saberes, tempo e aprendizagem do trabalho no magistério. Educação \& Sociedade, Campinas, SP, n. 73, p. 209-244, dez. 2000.

Recebido em: 11.01.2016 Aprovado em: 15.03.2016

Sandra Novais Sousa é Especialista em Alfabetização (IESF-2006), Coordenação Pedagógica (UCDB-2014) e Gestão Escolar (UNIASSELVI-2014). Mestre em Educação (UEMS-2014) e doutoranda em Educação (UFMS). Participante do Grupo de Estudos e Pesquisas em Antropologia e Sociologia da Educação (GEPASE) e do Grupo de Estudo e Pesquisa em Narrativas Formativas (GEPENAF). Atua como Coordenadora Pedagógica, na Secretaria de Educação do Estado do Mato Grosso do Sul, e professora alfabetizadora, na Secretaria Municipal de Educação de Campo Grande-MS. Tem experiência na área de Educação, com ênfase em alfabetização e letramento, políticas públicas de formação de professores, uso das TIC, na educação, coordenação e gestão escolar. E-mail: sandnovais@hotmail.com.

Jacira Helena do Valle Pereira Assis é Mestre em Educação, pela Universidade Federal de Mato Grosso do Sul e Doutora em Educação, pela Universidade de São Paulo. Líder do Grupo de Estudos e Pesquisas em Antropologia e Sociologia da Educação (GEPASE), vinculado à linha de pesquisa Escola, Cultura e Disciplinas Escolares da UFMS. Atualmente, é professora associada da Universidade Federal de Mato Grosso do Sul e Coordenadora do Programa de Pós-Graduação em Educação (cursos de Mestrado e Doutorado) CCHS/UFMS. Tem experiência na área de Educação, com ênfase em Sociologia da Educação, atuando principalmente nos seguintes temas: memória e memorialistas, fronteira e diversidade cultural, famílias e escolas. E-mail: jpereira.dou@terra.com.br.

Eliane Greice Davanço Nogueira é Doutora em Educação, pela Universidade Estadual de Campinas (2006). Professora da Universidade Estadual de Mato Grosso do Sul, no curso de Pedagogia, na unidade de Campo Grande, no programa de mestrado em Educação, na unidade de Paranaíba, e no programa de mestrado Profissional de Educação, na unidade de Campo Grande. Líder do grupo de estudos e pesquisas em narrativas formativas (GEPENAF) e membro do grupo de estudos e pesquisas em educação continuada (GEPEC). Tem experiência na área de Educação, com ênfase em Formação de Professores, atuando principalmente nos seguintes temas: formação de professores, escrita autobiográfica, pesquisa-formação, educação infantil, alfabetização e psicologia.

Universidade Federal de Mato Grosso do Sul

Programa de Pós-Graduação em Educação

Centro de Ciências Humanas e Sociais - Cidade Universitária s/n - Caixa Postal 549 